\title{
Cultura y política en el movimiento obrero en los inicios del orden democrático argentino. Reflexiones sobre la ocupación de Ford Motor (junio-julio 1985)
}

(4)andro Molinaro

CEHTI - Universidad de Buenos Aires, Argentina / leandromolinaro@gmail.com

Fecha de recepción: 30/9/2018. Fecha de aceptación: 7/2/2019.

\begin{abstract}
Resumen
El artículo aborda la ocupación de la planta Ford Motor de General Pacheco (Zona Norte del GBA), acontecida entre el 26 de junio y el 14 de julio de 1985 . El objetivo específico radica en analizar las prácticas de la organización interna en la ocupación de esta planta automotriz, intentando vislumbrar la experiencia y la conciencia de militantes y activistas obreros en esta lucha. En la primera parte realizamos una breve referencia a la coyuntura general del período, en la segunda sección establecemos una descripción del hecho y en el tercer apartado presentamos un análisis en base a categorías teóricas de los autores Edward Thompson, Raymond Williams, Antonio Gramsci y Raphael Samuel.
\end{abstract}

Culture and politics in the labour movement at the beginning of Argentine democratic order. Reflections on Ford Motor occupation (June-July 1985)

\footnotetext{
Abstract

This article tackles the occupation of Ford Motor Plant in General Pacheco (North of Buenos Aires Province), which took place between June 26th and July 14th 1985 . Its specific goal lies in analysing the practices of the internal organisation in the occupation of this automobile plant, attempting to discern the experience and consciousness of the activist workers in this struggle. In the first part, a brief reference is made to the general situation of the period, in the second part the actual fact is described and in the third one, a theoretical analysis is presented on the basis of those theoretical categories proposed by the following authors: Edward Thompson, Raymond Williams, Antonio Gramsci y Raphael Samuel.
}

Palabras clave

Ford

ocupación fabril cultura de izquierda
Keywords

Ford

factory occupation left-wing culture 
1. acia la década de 1980 la región del AMBA abarcaba Capital Federal y 19 partidos situados en el Gran Buenos Aires (GBA): Almirante Brown, Avellaneda, Berazategui, Esteban Echeverría, Florencio Varela, Gral. San Martín, Gral. Sarmiento, La Matanza, Lanús, Lomas de Zamora, Merlo, Moreno, Morón, Quilmes, San Fernando, San Isidro, Tres de Febrero, Tigre y Vicente López.

2. De la información relevada en distintas publicaciones pudimos observar que durante este período fueron ocupados los siguientes establecimientos siguientes establecimientos: Ford Motor S.A. (Zona Norte,

Gran Buenos Aires); metalúrgica Volcán, frigorífico Tres Cruces, taller grafico Roto-arg, los bancos Italia y Río de la Plata, Santurce, Los Pinos, Cabildo, Unicor y Juncal (Capital Federal); cristalería La Esperanza (Bernal); plásticos Viplastic (Burzaco); textil Tejidos Universal y Banco de la Empresa Cooperativo (Mar del Plata); cementera "Juan Minetti” y bodegas

Furlotti (Mendoza); baterías Buscema

(Paraná); frigorífico Formosa (Formosa); maderera Maderales (General San Martín, Chaco); Bodega Luchessi y Banco Regional Cooperativo (Córdoba); metalúrgica Carrasco, Acero Bragado y cristalería Cuyo (Rosario).

3. Pozzi y Schneider (1994) definen a los militantes y activistas como una minoría politizada que "cumple un papel clave en cuanto a la movilización social, a las reivindicaciones y a la capacidad de acción de la clase".

\section{Introducción}

Este trabajo se enmarca en el estudio sobre el movimiento obrero entre 1982 y 1989 en la región del Área Metropolitana de Buenos Aires. ${ }^{1}$ Sostenemos que para ello no alcanza con estudiar la relación entre Estado, empresarios y dirigencias sindicales, si no que resulta preciso tener en cuenta las acciones de las bases ya que consideramos que las mismas repercuten en las pugnas superestructurales. Por ello nos enfocamos principalmente en las luchas "desde abajo", teniendo en cuenta la inserción de diferentes agrupaciones políticas, en particular las izquierdas, en el movimiento obrero para resistir la embestida del gobierno y el empresariado. Para este escrito nos enfocamos en la ocupación de la planta Ford Motor de General Pacheco (Zona Norte del GBA), acontecida entre el 26 de junio y el 14 de julio de 1985. Lejos de ser un fenómeno aislado, la ocupación de esta planta fue una de las aproximadamente veinte tomas de lugares de trabajo ocurridas entre mayo y julio de $1985 .^{2}$ Esta modalidad de lucha constituía, por un lado, una continuidad de las experiencias obreras de resistencia de décadas anteriores, y por otro, implicaba prácticas de oposición que venían ocurriendo en diversos lugares de trabajo desde finales de la última dictadura militar. Nos centramos en el caso Ford debido a su impacto en el período dado la cantidad de operarios involucrados, por tratarse de una patronal transnacional, por la activa participación del gobierno de Alfonsín y la dirigencia del SMATA contra esta medida de fuerza, y por la repercusión mediática que generó la acción de los operarios.

El objetivo específico de este trabajo radica en analizar las prácticas de la organización interna en la ocupación de esta planta automotriz, intentando vislumbrar la experiencia y la conciencia de militantes y activistas obreros en esta lucha. ${ }^{3}$ Para ello nos serán de utilidad categorías teóricas de autores como Edward Thompson, Raymond Williams, Antonio Gramsci y Raphael Samuel. Como insumo utilizamos, principalmente, fuentes escritas (diarios nacionales y prensa partidaria) y, también, una entrevista realizada a uno de los obreros protagonistas de la ocupación. El escrito se encuentra organizado en diferentes secciones: en la primera realizamos una breve referencia a la coyuntura general del período, en la segunda sección establecemos una descripción del hecho y en el tercer apartado presentamos un análisis teórico en base a los autores antes mencionados.

\section{Los primeros años de la naciente democracia}

En octubre de 1983 triunfó el candidato de la Unión Cívica Radical (UCR), Raúl Alfonsín, siendo la primera vez que el Partido Justicialista (PJ) fuera derrotado en una elección presidencial sin ningún tipo de restricciones. El marco económico en el que se dio la restauración democrática indicaba una situación muy delicada para la clase trabajadora: entre 1974 y 1983 los salarios reales habían sido reducidos en un $20 \%$ y el nivel de ocupación laboral había disminuido un $34,3 \%$, con un consecuente aumento en la explotación de los trabajadores empleados. Asimismo, en 1983 la inflación había sido del 433,7\% anual y del 20\% mensual (el doble que en 1982). En momentos de la asunción de Alfonsín a la presidencia, el monto de la deuda externa ascendía 45.067 millones de dólares (equivalente a las exportaciones del país de cinco años) y el déficit fiscal equivalía al 15,6\% del PBI (Damill y Frenkel, 1993).

El primer ministro de economía del gobierno, Bernardo Grinspun, realizó un diagnóstico equivocado sobre la situación, sin percibir claramente las consecuencias de los cambios estructurales ocurridos en el país durante el "Proceso de Reorganización Nacional". Ni los sectores más concentrados de la burguesía transnacional ni los representantes del empresariado local, junto a la dirigencia sindical, aceptaron el plan económico trazado por Grinspun (Pesce, 2006). Como resultado de ello, durante 1984 la administración 
radical nunca pudo controlar la inflación, la cual se elevó a 683,4\% anual. Hacia 1985 Alfonsín trazó un cambio de rumbo reemplazando a Grinspun por Juan Sourrouille. Con la intención de solucionar los problemas del déficit fiscal, la inflación y el endeudamiento, Sourrouille diseñó el denominado Plan Austral, una puesta en marcha de medidas estabilizadoras heterodoxas para controlar la inflación como parte de un acuerdo con el Fondo Monetario Internacional (FMI) y los sectores más concentrados del empresariado (Ortiz y Schorr, 2006). El plan económico entró en vigencia el 14 de junio de 1985, provocando consecuencias recesivas en distintas ramas industriales como la automotriz.

Mientras el gobierno intentaba encauzar la problemática económica, también trazó como objetivo inaugurar un nuevo tiempo político. Eduardo Glavich y Alberto Bonnet (1993) señalan que el alfonsinismo intentó construir una hegemonía política basada en discursos y prácticas "democratizantes" que se sustentaban en la derrota de los movimientos sociales de los años 60 y 70 y el resurgimiento de reivindicaciones democráticas en el ocaso de la última dictadura militar. En sentido similar consideramos que el alfonsinismo planteó una concepción en la cual el sujeto central era la ciudadanía, la cual debía ser respaldada por un Estado de Derecho que desde un renovado marco moral y jurídico desterraría las lógicas autoritarias y corporativas del pasado reciente. Pueden leerse en este sentido los primeros decretos gubernamentales, la sanción de los decretos 157 y 158 (que ordenaban enjuiciar a las cúpulas de las organizaciones revolucionarias armadas y a la de las Fuerzas Armadas de la segunda mitad de los años setenta), la creación e investigación de la Comisión Nacional sobre la Desaparición de Personas (CONADEP) y, posteriormente, el juicio a los ex comandantes de las tres primeras Juntas Militares llevado a cabo entre abril y diciembre de 1985. Estas acciones basadas en el relato de la "teoría de los dos demonios" buscaban circunscribir las responsabilidades de la conflictividad política y social de los años setenta, por un lado, en la "extrema izquierda", representada principalmente por las organizaciones revolucionarias, y, por otro, en la extrema derecha, personificada primero en la Triple A y, luego en la dictadura militar. Estos dos "demonios" habrían atacado a una sociedad "inocente". De esta manera, este relato oscurecía las características de la lucha de clases de los años sesenta y setenta ocultando las causas y objetivos del genocidio llevado a cabo por el Estado. En la coyuntura de la restauración democrática los proyectos alternativos y antisistémicos reivindicados por organizaciones políticas y sindicales combativas y de izquierda quedaban signados en esta demonización.

En este marco, la dirigencia sindical, en particular los nucleamientos peronistas que dirigían la Confederación General del Trabajo (CGT), era caracterizada por el gobierno como una "corporación" ajena al orden democrático. El alfonsinismo planteaba que el movimiento sindical debía ser profundamente refundado desde el Estado para que se adaptase a los nuevos tiempos políticos. ${ }^{4}$ Desde esta concepción, el gobierno de Alfonsín intentó en sus inicios una ofensiva contra la dirigencia gremial a través del proyecto de ley de "reordenamiento y democratización sindical". Impulsado por el ministro de trabajo, Antonio Mucci, el proyecto establecía que el Estado regulase las elecciones sindicales. ${ }^{5}$ Si bien logró la aprobación en la Cámara de Diputados en el Senado fue rechazado por dos votos en marzo de 1984. Tras esta derrota legislativa, el gobierno cambiaría a una táctica conciliadora hacia estas direcciones gremiales con la asunción en el Ministerio de Trabajo de, primero, Juan Manuel Casella en reemplazo de Mucci, y luego de Hugo Barrionuevo a fines de octubre de 1984. Este último, un sindicalista de origen peronista y proveniente del sindicato fideero, sería el encargado de negociar con las cúpulas gremiales la normalización de las asociaciones sindicales en situación irregular desde mediados de la década de 1970.

Al interior de la CGT, reunificada desde enero de $1984,{ }^{6}$ predominaban cuatro nucleamientos identificados con diferentes vertientes del peronismo: las 62 Organizaciones, la Comisión Nacional de los 25, la Comisión de Gestión y Trabajo y la Comisión de
4. Ya en la campaña electoral de 1983 Alfonsín había denunciado la existencia de un supuesto pacto militar-sindical, el cual señalaba a dirigentes alineados en la CGT Brasil, en particular al sector de las 62 Organizaciones, como beneficiados por el gobierno en la normalización de los grandes gremios. Según esta denuncia, a cambio los líderes de esa central se habrían comprometido a garantizar la impunidad de militares involucrados en la represión estatal y otros ilícitos cometidos en los últimos años (Novaro y Palermo, 2003).

5. Varias obras abordan la "Ley Mucci” centrándose, desde diferentes miradas, en la relación entre el Estado y la dirigencia sindical durante los meses que duró el debate en torno a este proyecto (diciembre 1983 a marzo de 1984). Véase Fernández, 1995; Lucita, 1985; Massano, 2012; Murillo, 2010; Senén González y Bosoer, 1993; Zorzoli, 2015.

6. La secretaría general de la central reunificada quedó en manos de cuatro dirigentes que expresaban a estos sectores: Saúl Ubaldini (líder de la Federación Obrera Cervecera Argentina, miembro de la Comisión Nacional de los 25 y hasta ese entonces Secretario General de la CGT Brasil), Jorge Triaca ( líder de la Unión de Obreros y Empleados Plásticos, la Comisión de Gestión y Trabajo y hasta ese momento Secretario General de la CGT Azopardo), Ramón Baldassini (Secretario General de la Federación de Obreros y Empleados de Correos y Telecomunicaciones) y Osvaldo Borda (Secretario General del Sindicato Obrero del Caucho, Anexo y Afines). 
7. Las figuras de mayor peso en el peronismo sindical estaban divididos en esta coyuntura. Las 62 Organizaciones, encabezada por Lorenzo Miguel, representaba el sector más ortodoxo peronismo. Miguel estaba alineado con la cúpula del PI derroada en las elecciones presidenciales de 1983, que mantenía la conducción del justicialismo. Comisión Nacional de los 25, a la que pertenecía el Sindicato de Mecánicos y Afines del Transporte Automotor (SMATA), era la agrupación opositora al miguelismo y se presentaba como la continuadora de "las corrientes combativas del movimiento obrero comprometidas con la restauración democrática”. En términos partidario apoyaba al denominado peronismo renovador, línea interna que buscaba tomar las riendas de un partido en crisis. En la CGT confluía, también, Jorge Triacca, quien había sido abiertamente colaboracionista con la última dictadura militar, y en este nuevo contexto se alineaba con los sectores empresariales que impulsaban la realización de reformas neoliberales (Belardinelli, 1994). 8. En estos sectores confluían la izquierda partidaria: el Movimiento al Socialismo (MAS), Partido Obrero (PO), Partido Comunista Revolucionario (PCR) y el Partido Comunista (PC). Y también sectores sindicales del peronismo que no respondían a ninguno de los nucleamientos antes mencionados. Todos los datos

fueron tomados de: Tabaré Areas,

"El plan amenazado", Somos, $\mathrm{N}^{\circ}$ 460, 12-7-1985, pp. 7, 8; Joaquín Morales Solá, "La ocupación, otros interlocutores", Clarín, 14-7-1985, p. 16.

9. Véase "Qué se juega en la lucha de Ford", Qué pasa, N 228, 17-7-1985, p. 4. Cabe agregar que la empresa Ford fue señalada como cómplice de la represión estatal y paraestatal de los años setenta con la colaboración en la entrega de listas de activistas de su compañía a la Triple A y el Ejército (Basualdo, 2006; Löbbe, 2006).

10. Información obtenida de: Miguel Delfini, obrero de Ford desde 1976 hasta 1985, activista del PCR, delegado, coordinador de la Comisión Interna y miembro de la Lista Naranja entre 1984 y 1985 . Entrevista realizada el 11 de febrero de 2017 en Escobar, Provincia de Buenos Aires. Entrevistador: Leandro Molinaro. los $20 .^{7}$ No obstante, estos nucleamientos no mantenían un control total del movimiento obrero. Según datos de la época la cúpula peronista, en todas sus variantes, controlaba el 90 por ciento de las conducciones nacionales de los gremios, el 80 por ciento de las conducciones de seccionales y el 70 por ciento de las comisiones internas. El 30 por ciento de las organizaciones de base estaban en manos de agrupaciones combativas y de izquierda fuera del control de la dirigencia sindical. ${ }^{8}$ En su enfrentamiento con el gobierno, entre 1984 y 1985, la CGT llevó a cabo tres paros generales, contando con un alto acatamiento y movilizaciones masivas (Iñigo Carrera, 2001; Novaro, 2009).

En paralelo, desde el último tramo de la última dictadura el movimiento obrero realizó múltiples acciones directas defensivas "desde abajo". En los lugares de trabajo, las bases, organizadas o no, impulsaron paros, ollas populares, movilizaciones y ocupaciones de fábricas (Pozzi y Schneider, 1994). Como mencionamos, entre mayo y julio de 1985 hubo una ola de tomas de establecimientos como medida defensiva de los trabajadores contra el cierre de los mismos, por despidos y atrasos salariales. El atractivo de estudiar este tipo de acciones radica en que, por un lado, éstas implicaban, potencialmente, una impugnación al sistema capitalista, en cuanto a que significaban una violación de la propiedad privada de los medios de producción de la burguesía. Y al mismo tiempo significaban una refutación a uno de los pilares del resurgido orden democrático debido a que recuperaba una experiencia obrera "demonizada" en esta coyuntura.

\section{La ocupación de Ford}

Varios autores ya han abordado el caso de la ocupación de Ford Motor (Abdala, 2015; García Allegrone, Partenio y Fernández Álvarez, 2003; Giniger et al, 2010; Hernández, 1985; Molinaro, 2013; Pozzi y Schneider, 1994; Rubio, 2017. En este apartado tomamos algunos elementos de ellos que nos resultan de utilidad para describir este enfrentamiento particular que se dio entre los obreros, por un lado, y la patronal, el gobierno de Alfonsín y la dirigencia del Sindicato de Mecánicos y Afines del Transporte Automotor (SMATA), asociación a la que pertenecían los trabajadores del establecimiento ubicado en General Pacheco, Zona Norte del GBA.

\section{Antecedentes}

Desde la década de 1970, la industria automotriz venía efectuando una reducción del personal a partir de los cambios en el sistema de producción a nivel internacional y por la situación de recesión y estancamiento existente en el país. Tras el golpe de Estado de 1976, Ford realizó despidos masivos y descabezó a la organización interna?. La complicidad militar-empresarial convirtió al extenso establecimiento automotriz de General Pacheco (unas 160 hectáreas) en uno de los sitios laborales más afectados por la represión de los años setenta, con 24 delegados secuestrados y torturados, y un centro clandestino de detención en su interior (AEyT de FLACSO et al, 2016). A pesar de esta situación, militantes del Partido Comunista Revolucionario y el Partido Socialista de los Trabajadores (el Movimiento Al Socialismo, a partir de 1982) realizaron un trabajo clandestino en la empresa durante los últimos años de la dictadura (Abdala, 2015; Giniger et al, 2010; Rubio, 2017). Además, hacia inicios de la década de 1980, el Partido Comunista, el PO, el peronismo y el radicalismo también contaban con militantes en el establecimiento. ${ }^{10}$

A nivel sindical, el SMATA se encontraba en vía de normalización. Tras siete años de intervención a nivel nacional, las principales agrupaciones peronistas del gremio que habían conservado el control de las seccionales del sindicato (la Lista Verde conducida 
por José Rodríguez; ${ }^{11}$ la agrupación Lealtad a Kloosterman, conducida por Rubén Cardozo; y el Movimiento Nacional de Unidad Automotriz - Lista 22 de Mayo) negociaron con el último gobierno militar la conformación de la una Comisión Normalizadora (Molinaro, 2016 y 2017). En cuanto al área geográfica de Ford, la Zona Norte, era dirigida, como todas las delegaciones del GBA y Capital Federal, por la Lista Verde. No obstante, esta agrupación contaba con poca inserción en Ford debido a su actitud pasiva ante la represión y despidos ocurridos en la empresa tras el golpe de Estado.

Con la reapertura democrática, los operarios de Ford pudieron reconstituir la Comisión Interna y el Cuerpo de Delegados, disueltos con la represión estatal de los años setenta, luego de un conflicto con la empresa y el gobierno de Alfonsín entre enero y marzo de 1984. En octubre de ese año se produjeron las elecciones nacionales del SMATA donde triunfó la Lista Verde, siendo elegido José Rodríguez como secretario general. Para dichas elecciones los activistas que provenían del PCR, el MAS y el PO conformaron la Lista Naranja (el PC apoyaba a la Lista Verde), cuya mayor representación se encontraba en la organización interna de Ford. Miguel Delfini, coordinador de la Comisión Interna de la planta de General Pacheco, fue su candidato a secretario general. También de Ford surgió el candidato de la principal oposición peronista a la Lista Verde, Jorge Castro de la agrupación Lealtad a Kloosterman que conformaría para estas elecciones la Lista Azul y Blanca. ${ }^{12} \mathrm{Si}$ bien Rodríguez ganó con el $50 \%$ de los votos a nivel nacional, en Ford el resultado fue diferente: la lista más votada fue la Azul y Blanca (52\%), seguida por la Lista Naranja (40\%) y la Lista Verde de Rodríguez en último lugar (7,9\%) (Santella, 2008).

Entre finales de 1984 y los primeros meses de 1985, Ford continuó con su política de reducción de personal iniciada durante la última dictadura militar. Hubo unos 850 obreros, entre ellos Jorge Castro de la Lista Azul y Blanca, que aceptaron el retiro voluntario. Esto le dio mayor peso a la Lista Naranja al interior del establecimiento. Tras varias denuncias de la Comisión Interna sobre las intenciones de la empresa de disminuir la fuente laboral, logró que esta última firmara un acta-acuerdo en la se comprometía a no realizar despidos hasta el 31 de julio. En este acuerdo no participó el SMATA ni el Ministerio de Trabajo. ${ }^{13}$ La aplicación del Plan Austral, en junio con sus efectos recesivos en la industria automotriz, acelerarían los planes de la empresa.

\section{El conflicto}

El 26 de junio, mediante una asamblea, unos 3800 operarios (sobre un total de aproximadamente 4500) decidieron ocupar la planta de General Pacheco. El desencadenante de tal decisión fue el despido de 33 trabajadores ocurrido el día anterior. Esto significaba un incumplimiento de la patronal del acta-acuerdo firmada el 17 de mayo. Ante la toma, la empresa mantuvo su posición y aplicó un lock out, suspendiendo la producción y ordenando a los capataces que se llevaran las herramientas de las diferentes secciones.

Desde un principio, el gobierno condenó el accionar de los trabajadores. Si bien el Ministro de Trabajo, Hugo Barrionuevo, intimó a la empresa a revisar la medida dispuesta, declaró ilegal la ocupación e instó a la Comisión Interna a desalojar la planta. ${ }^{14}$ Además, el gobierno se negó a declarar la conciliación obligatoria para retrotraer la situación al momento previo al conflicto. Los obreros mantuvieron su posición argumentando que con la toma defendían sus puestos de trabajo y que era la empresa la responsable de esa situación al aplicar el lock out. La compañía se negó a aceptar esta intimación argumentando que la ocupación atacaba la propiedad privada. Además, justificaba los despidos en motivos disciplinarios, principalmente ausentismo elevado crónico, cuestión que según los voceros de la patronal, no se encontraban incluidos dentro del acta-acuerdo del 17 de mayo. ${ }^{15}$
11. La Lista Verde formaba parte de la Comisión de los 25, la cual había organizado el primer paro general contra la dictadura en abril 1979 y había sido uno de los nucleamientos principales que habían conformado la CGT Brasil en 1980. Algunos analistas de la coyuntura lo caracterizaban como un sector combativo al interior del movimiento obrero. Véase: Abós, 1986; “Crisis en la CGT-RA", La Nación, 212-1983, p. 6. A nivel partidario en 1985 , la Comisión de los 25 era cercana al peronismo renovador, tendencia que buscaba tomar las riendas del PJ en crisis desde la derrota en la elección presidencial de octubre de 1983.

12. La Lista Azul y Blanca contaba con vínculos con las 62 Organizaciones y con el sector del peronismo bonaerense al que pertenecían Herminio Iglesias y el diputado Norberto Imbelloni. Ricardo Roa, "Las riesgosas aristas del conflicto", Clarín, 1-7-1985, pp. 14, 15 .

13. Ante la pregunta sobre por qué el acta-acuerdo fue firmada por la empresa y la Comisión Interna sin la participación de la dirección del SMATA ni el Ministerio de Trabajo, Delfini relata que: "Nosotros se la habíamos dado al sindicato para que la llevara y no la llevó. No, no. Se fue preparando una encerrona. O sea, la posición de la empresa fue: 'Vamos a acuerdo, esta Comisión Interna no'. Ya era molesto tener una Comisión Interna así. Para Alfonsín, para Rodríguez y para la empresa" (Miguel Delfini. Entrevista realizada el 11 de febrero de 2017 en Escobar, Provincia de Buenos Aires. Entrevistador: Leandro Molinaro).

14. “Recíproca contumacia”, Crónica (1era. edición), 29-6-1985, p. 2.

15. Solicitada "Por qué Ford no se va", Crónica (1era. edición), 10-7-1985, p. 11. 
16. Datos tomados de: Ricardo Roa, "Las riesgosas aristas del conflicto", Clarín, 1-7-1985, pp. 14, 15 .

17. Véase: "Adhesiones", Hoy, servir al pueblo, $N^{\circ} 76,3-7-1985$, pp. 6,7 ; "Adhesiones de otros sectores; documento”, Crónica (1era. edición), p. 2.

18. “Ubaldini respaldó a los trabajadores en conflicto”, Clarín, 12-7-1985, p. 4. 19. Dado el gran tamaño del complejo, los operarios en conflicto rodearon las puertas de la fábrica con autos para tener un control estricto de las entradas y salidas. Para albergar a la gran cantidad de trabajadores que permanecían en el establecimiento improvisaron dormitorios en las fábricas y se distribuían alimentos recolectados a través de donaciones.

También puede observarse una disciplina aceitada que incluía la prohibición de bebidas alcohólicas y el establecimiento de turnos rotativos de guardia de dos horas. Los familiares tenían horario de visita de 9 a 19 horas. Además, la comisión interna se encargaba de redactar comunicados de prensa y distribuir

piquetes para controlar cada espacio del complejo. Datos tomados de:

"Obreros atrincherados en la planta

de Ford”, Crónica (sta. edición), pp. 10, 11; Luis Castillejos, "Motores al rojo vivo", Somos, $\mathrm{N}^{\circ} 459,5-7-1985$, p. 13; Tabaré Areas, "El plan amenazado", Somos, $\mathrm{N}^{\circ} 460,12-7-1985$, pp. $7,8$. 20. "Cuando los obreros dirigieron la Ford", Hoy, servir al pueblo, $\mathrm{N}^{\circ} 82,14-8-1985$, p. 4.

21. Cabe agregar que mientras se desarrollaba la ocupación de la planta existieron denuncias sobre persecuciones, amenazas e intimidaciones a familiares de trabajadores en sus hogares por bandas parapoliciales.

Este clima represivo nos muestra que el Estado y la compañía no sólo se valían de medios legales y declaraciones públicas para amedrentar a los obreros que permanecían en la plan-

ta. "Procesan a trabajadores de Ford", Crónica (1era. edición), 9-7-1985, p. 2. 22. “'Nadie puede tolerar la ocupación de la Ford', dijo Alfonsín", Clarín, 14-7-1985, pp. 4, 5. 23. "Fue desocupada la planta Ford. Espectacular dispositivo policial", Crónica (1era. edición), 15-7-1985, pp. 2, 3.
La ocupación fue motorizada por la Comisión interna y el Cuerpo de Delegados en los cuales, como mencionamos, predominaba la Lista Naranja, aunque no era la única agrupación. El coordinador de la Comisión Interna, Miguel Delfini, era un activista del PCR. Este organismo también contaba con delegados que pertenecían a la Lista Azul y Blanca y otros sectores del peronismo, y también un radical. En el Cuerpo de Delegados había activistas del PC, el MAS, y el PO, además de independientes. ${ }^{16}$ Recibieron adhesiones y muestras de solidaridad de políticos de diversas corrientes (principalmente dirigentes de los partidos de izquierda que formaban parte de la Lista Naranja, el justicialismo, el PC y el Partido Intransigente), centros de estudiantes de escuelas secundarias y universitarios, Madres de Plaza de Mayo y miembros de otras organizaciones de derechos humanos (como Adolfo Pérez Esquivel), comisiones internas de otras empresas y artistas (muchos de ellos participaron de un festival en apoyo a los trabajadores de Ford realizado el 14 de julio). ${ }^{17}$ También lograron apoyo en otros países como el de los obreros de Ford Inglaterra (quienes realizaron un paro solidario de cuatro horas), Ford Uruguay y la Central Única de los Trabajadores de Brasil (Pozzi y Schneider, 1994).

La medida fue rechazada y criticada por la conducción nacional del SMATA. Institucionalmente, la CGT no dio muestras de apoyo a la ocupación, debido al peso que tenía la Comisión de los 25 (a la que pertenecía el sindicato mecánico) dentro del mismo. Si bien el cosecretario general Ubaldini defendió a los trabajadores en conflicto, ${ }^{18}$ la Confederación no impulsó medidas de fuerza en respaldo a la lucha de los mecánicos.

Desde el comienzo, la toma tuvo una organización rigurosa. ${ }^{19}$ La gran mayoría de los operarios permanecieron en la fábrica solidarizándose con sus compañeros despedidos. Las decisiones eran tomadas por las asambleas de cada sección y, luego, en asamblea general. Para contrarrestar las acusaciones de la empresa sobre el deterioro de la maquinaria, los trabajadores decidieron poner la planta en funcionamiento entre el jueves 11 y el viernes 12 de julio con turnos de 4 horas. Según el periódico del PCR, participaron en las actividades laborales 3 mil obreros mientras que otros mil permanecieron en los puestos de guardia. Se llevaron a cabo tareas en la planta de camiones, motores, estampados y montajes. Al poner en marcha la producción, buscaban demostrar públicamente que las instalaciones se encontraban en perfectas condiciones. ${ }^{20}$

La presión en aumento de la empresa, sumada a las acciones de persecución de la Comisión Interna y el Cuerpo de Delegados desde el Poder Judicial y el gobierno de Alfonsín, y la falta de apoyo del SMATA y la CGT fueron los factores principales que desencadenaron el desalojo de la fábrica tras dieciocho días de ocupación. ${ }^{21}$ Horas antes del final, Alfonsín condenó la ocupación declarando: "no existe ningún país en el mundo bajo cualquier sistema político que tolere este tipo de ocupación por lo que nosotros tenemos que recurrir a la Justicia y actuar de acuerdo con la ley". ${ }^{22}$ La crítica tenía como objetivo legitimar el accionar represivo contra los trabajadores poniéndolos por fuera de los límites de lo que el régimen democrático podía tolerar.

En la madrugada del 14 de julio la planta fue rodeada por un dispositivo policial que contó con 2000 efectivos armados, 200 patrulleros, carros de asalto, tres helicópteros de combate, policía motorizada y montada, perros, reflectores y tanquetas. Ante esta situación amenazante, los obreros reunidos en asamblea decidieron resistir, aunque ante la disparidad de los bandos, optaron por que la Comisión Interna negociara un desalojo pacífico con el juez federal Carlos Valdez, encargado del operativo policial. ${ }^{23}$

En los días posteriores al desalojo, la empresa tomó represalias: ratificó el despido de los 33 operarios previos a la protesta y dejó cesantes a otros 338, entre los cuales se incluía toda la Comisión Interna y el Cuerpo de Delegados. Además, fueron 
procesados por el juez penal de San Isidro, Ángel Papalia, todos los miembros de la Comisión Interna y un delegado del comedor. El 24 de julio, el presidente de Ford Argentina, Robert Sparvero, el Ministro Hugo Barrionuevo y el líder del SMATA, José Rodríguez, firmaron un acuerdo con el cual se daba por cerrado el conflicto y legitimaba la posición de la empresa. Además, la dirección del sindicato impuso unilateralmente una nueva Comisión Interna encargada de "apaciguar" a los obreros que no habían sido cesanteados por el conflicto. De esta manera, la influencia de la Lista Naranja dentro de la planta fue suprimida.

\section{Cultura y política de izquierda, experiencia y hegemonía}

En el análisis de la ocupación de Ford nos resulta de gran utilidad una serie de categorías propuestas por autores que piensan el vínculo entre cultura y política en la clase obrera. Tomamos como punto de partida la célebre cita del historiador inglés E.P. Thompson:

\begin{abstract}
Las personas se encuentran en una sociedad estructurada en modos determinados, que pueden ser relaciones de producción, donde experimentan la explotación (o la necesidad de mantener el poder sobre los explotados), identifican puntos de interés antagónicos, comienzan a luchar por estas cuestiones y en el proceso de lucha se descubren como clase, y llegan a conocer este descubrimiento como conciencia de clase. La clase y la conciencia son siempre las últimas y no las primeras fases del proceso real histórico (Thompson, 1989).
\end{abstract}

La experiencia de Ford debe enmarcarse en la lucha de las clases enfrentadas en la coyuntura de la sociedad argentina de la década de 1980. Por lo tanto al observar la lucha, si bien nos centramos en el movimiento obrero, no podemos obviar el rol de la patronal, el Estado y la dirigencia sindical del SMATA debido a que fueron los antagonistas en este conflicto. En cuanto a los operarios, resulta necesario destacar la inserción de agrupaciones de izquierda en la organización de base de la planta automotriz para la transmisión de experiencias de luchas de la clase obrera. El rol de estos partidos puede observarse en el siguiente relato de Miguel Delfini, coordinador de la Comisión Interna y activista del PCR, sobre cómo fue pensada la ocupación de Ford:

Pregunta (P): Cuando deciden la toma: ¿En qué modelo de toma se basaban?

Miguel Delfini (MD): Yo me basaba en dos: la del frigorífico Lisandro de la Torre y la de Perdriel en el SMATA Córdoba. Había estudiado esas.

P: ¿Junto a quiénes?

MD: Con los compañeros de la Comisión Interna, con los compañeros del partido. La habíamos preparado bastante tiempo antes. La veníamos venir. Después, fue lo que fue. No esperábamos que fuera lo que fuera. Nosotros creíamos que íbamos a una toma de dos días, pero la vida fue más rica de lo que uno se imagina. ${ }^{24}$

De lo señalado por Delfini, el partido maoísta actuó como transmisor de experiencias de lucha: la toma del frigorífico porteño Lisandro de la Torre en 1959 y la de la fábrica automotriz cordobesa Perdriel en $1970 .{ }^{25}$ En esta última, el PCR había tenido un destacado papel. El partido resultó fundamental en Ford dado que colaboró e incentivó a los activistas de la Comisión Interna para impulsar la ocupación fabril ante la amenaza de despidos masivos. En otro pasaje de la entrevista, Delfini describía la forma en que fue decidida la puesta en marcha de la producción bajo control obrero. También se puede observar aquí la importancia de la agrupación de izquierda:
24. Miguel Delfini. Entrevista realizada el 11 de febrero de 2017 en Escobar, Provincia de Buenos Aires. Entrevistador: Leandro Molinaro.

25. Sobre la toma del frigorífico Lisandro de la Torre véase, entre otros: James, 1999; Salas, 2006; Schneider, 2005. Acerca de la toma de la fábrica Perdriel: Laufer, 2017; Lissandrelo, 2013. 
26. Miguel Delfini. Entrevista realizada el 11 de febrero de 2017 en Escobar, Provincia de Buenos Aires. Entrevistador: Leandro Molinaro.
$\mathrm{MD}$ : $\mathrm{Y}$ en esos días vino Otto Vargas ( $\mathrm{N}$ del A: secretario general del PCR) a la fábrica. Entró, conversamos. Y me acuerdo que él me dijo: "Mirá, Miguel, éste es un conflicto muy duro. Se puede perder pero hay que mantener las banderitas como en Perdriel".

P: ¿Otto Vargas, entonces, les propuso que pongan en marcha la producción?

MD: Sí. Hubo dos que nos propusieron eso. Rubén Roura, subdelegado mío, y Otto Vargas.

\section{LM: ¿Y Rubén era del PCR también?}

MD: Sí, pero lo había propuesto el Cuerpo de Delegados. Le dije a Otto: "Bueno, vamos a eso". [...] (Vargas) dijo "Mantengamos los principios porque si acá vamos a una derrota, vamos a provocar desazón en toda la clase obrera que nos está mirando". Claro, es así. Vos un conflicto lo podés perder con la banderita en alto y hoy me venís a reportear. Ahora, un conflicto lo entregaste, y creás desazón en el movimiento obrero, entregás...

\section{$[\ldots]$}

P: ¿La mayoría de los obreros estuvieron de acuerdo con la puesta en producción?

MD: Sí, sí, hicimos asamblea y todos estuvieron de acuerdo.

\section{P: ¿Cómo se vivió eso?}

MD: Fue un hecho conmovedor. Porque todo el mundo estaba. Hubo asistencia perfecta ese día. [...] volver a trabajar y producir reavivó el espíritu. ${ }^{26}$

Más allá que, como señala Abdala (2015), no todos los partidos de izquierda con inserción en la fábrica estuvieron de acuerdo con la propuesta de ocupación de la planta realizada por los activistas del PCR, éstos también ponían a disposición de los obreros otras experiencias y perspectivas de la situación. Este historiador cita un testimonio de un delegado, militante del MAS, que arroja luz sobre estas diferencias:

Recuerdo que en el local de Pacheco nosotros con la gente del MAS, veíamos la posibilidad de que iba a venir un conflicto gordo por el tema de los despidos porque había una premisa de no permitir los despidos arbitrarios en la fábrica... y se hizo una discusión con respecto a la posibilidad de que se dé la toma, y que nosotros discutíamos que vos no podés meterte en un conflicto de estas características porque es un quiebre muy duro... es como una especie de "todo o nada", se puede perder la organización de conjunto, y hay que medir un montón de cosas... En esa época se estaba dando el Plan Austral, y había una situación de que como todo plan nuevo que da la burguesía, de expectativa. Y se veía un poco como que las condiciones políticas no serían las mejores para poder encarar una lucha. Entonces fueron compañeros que después militaron en el PCR, que eran delegados, a discutir con nosotros allá en el local de Pacheco... y ellos ya se ve que estaban con la línea de tomar la fábrica, porque se fueron como que todas las cuestiones que se planteaban eran como excusas para no luchar. Me acuerdo, un compañero del PCR decía: "al final, ustedes son revolucionarios de cartón", que teníamos muchos problemas para hacer algo, y entonces, te presionaban "por izquierda" en ese sentido, como para decir que impulsemos la toma... ya ellos venían hablando de la toma (Abdala, 2015).

Por otro lado, durante la ocupación y después del fin de la misma, el PO proponía cortar la Panamericana (la ruta principal de acceso a la Capital Federal desde Zona Norte) junto a otras Comisiones Internas de establecimientos de la región, rememorando la 
experiencia de la coordinadora interfabril de Zona Norte conformada en 1975 en los tiempos del Rodrigazo. No obstante, cabe agregar que, igualmente, todas estas agrupaciones dieron apoyo a los obreros de Ford una vez decidida la toma, y que las diferencias entre las mismas saldrían a la luz tras el desalojo de los obreros (Molinaro, 2013).

Basándonos en Raphael Samuel (2006) ${ }^{27}$ quien estudia el vínculo entre la clase obrera inglesa y el PC en la década de 1920, podemos señalar que la interacción entre partidos de izquierda con los obreros de Ford resultó de importancia en la politización de estos últimos. En el caso analizado consideramos que resulta necesario articular lo postulado por Thompson acerca de que la conciencia surge de la experiencia de la explotación, con lo planteado por Samuel en cuanto a la importancia de las organizaciones de izquierda en la toma de conciencia (para sí) de los operarios, al menos de los que cumplieron un papel activo en la organización y desarrollo de la toma y lograron movilizar a la mayoría de ellos. Es decir, de la construcción de un "nosotros", los obreros que participaron de la toma y la puesta en marcha de la terminal automotriz, y un "ellos": la patronal, el gobierno y, también, la conducción del SMATA encabezada por José Rodríguez de la Lista Verde. Siguiendo el testimonio de Delfini:

El gobierno no podía retroceder. La empresa no podía retroceder. Y nosotros tampoco. [...] [José] Rodríguez no nos quería porque éramos un mal ejemplo. Alfonsín necesitaba avalar... pedía paz social y necesitaba el Plan Austral [...] Lo fundamental era que iban a despedir 1500 y con ellos a la Comisión Interna. Por lo tanto, dijimos... acá el tema era así: Alfonsín quería ganar, Rodríguez quería ganar, la empresa quería ganar. E iban a perder los obreros. Nosotros dijimos “bueno, la situación es dura pero ustedes también van a perder". ${ }^{28}$

Cabe detenerse un momento en la dirigencia sindical, la cual surge como un "otro" en los mismos términos que el gobierno y la patronal. Resulta claro que Lista Verde tenía mala imagen en Ford desde el golpe de estado de 1976, debido a su pasividad ante los secuestros y torturas ejercidos contra delegados de la empresa. En ningún momento de la toma de 1985 se mostró favorable a los obreros. La fotografía del apretón de manos entre Rodríguez y el presidente de la Ford Motor Argentina, Robert Sparvero, tras los despidos masivos sintetizó el rol de la burocracia del SMATA. Lejos de la imagen de "duro" o de protagonista de la oposición a la dictadura que le otorgaban algunos autores y medios de comunicación, Rodríguez sintetizaba la figura de burócrata sindical que como primer objetivo buscó reproducir sus intereses como parte de una casta, los cuales colisionaban con los intereses de los obreros atacados por la patronal de Ford. ${ }^{29}$

Frente a esta ofensiva, la modalidad de toma con producción bajo control obrero, llevada a cabo por los operarios, puede ser conceptuada como parte de lo que Williams (2009) entiende como cultura residual del movimiento obrero. Es decir, ciertas experiencias del pasado (las ocupaciones fabriles eran una herramienta histórica de lucha) que, en el contexto de reapertura democrática, no podían ser expresadas en términos de cultura dominante. Tanto la última dictadura militar, con la represión genocida contra el movimiento obrero y las agrupaciones revolucionarias, como el régimen democrático, que impulsaba la "teoría de los dos demonios", condenaban modalidades de luchas tales como la ocupación fabril, las asambleas o, inclusive, las huelgas. En la coyuntura de 1985, la cultura dominante del "nunca más" incluía la demonización de dichas prácticas. ${ }^{30}$

El concepto de cultura dominante de Williams se encuentra vinculado con el de hegemonía de Gramsci, es decir con "el conjunto de actividades prácticas y teóricas con que la clase dirigente no sólo justifica y mantiene su dominio sino que logra
27. Extraído de Mastrángelo, 2011.

28. Miguel Delfini. Entrevista realizada el 11 de febrero de 2017 en Escobar, Provincia de Buenos Aires. Entrevistador: Leandro Molinaro.

29. En una investigación sobre el SMATA en los años recientes, Paula Varela y Débora Vasallo (2016) exponen que la ocupación de Ford también impactó en la identidad de la cúpula de los mecánicos. Para los dirigentes de la Lista Verde este conflicto actúa como ejemplo de cómo no debe actuar una organización de base y lo peligroso que resulta la izquierda para la clase obrera al caracterizar a la empresa como enemiga de los trabajadores. Por el contrario, en el discurso dirigencial la patronal es construida como creadora de puestos laborales.

30. Consideramos que las acciones y discursos desde el Estado, basados en la "teoría de los dos demonios", en esta coyuntura no pueden ser considerados en términos de lo que Williams denomina cultura emergente (nuevos significados, prácticas y tipos de relaciones que configuran elementos alternativos u opositores a la cultura dominante), sino como una nueva fase de la cultura dominante. 
31. Como mencionamos, el Ministerio de Trabajo declaró ilegal la toma y Alfonsín la condenó horas antes del desalojo. Además, hubo declaraciones públicas de funcionarios radicales que giraban en torno a "garantizar la vigencia del orden constitucional, donde la propiedad privada es una de sus piedras basales" (Germán López, secretario general de la presidencia,), señalar la ocupación como una "violación del sistema jurídico" que excedía “los límites del sistema legal” (Antonio Tróccoli, ministro del interior), y como un "acto delictual" (Juan Carlos

Pugliese, presidente de la Cámara de Diputados). Tabaré Areas, "El plan amenazado", Somos, $\mathrm{N}^{\circ}$ 460, 12-71985, pp. 7, 8; "Tróccoli: Acto de fuerza que viola sistema jurídico" y "Pugliese: 'la toma, un acto delictual'”, Crónica (1era. edición), 13-7-1985, p. 3. 32. "Nuestro aporte a un balance de la lucha de Ford", Prensa Obrera, $\mathrm{N}^{\circ} 106,25-7-1985$, p. 5 . obtener el consenso activo de los gobernados" (Gramsci, 1999). Tanto la empresa como el gobierno de Alfonsín se ampararon en la democracia y en la legalidad para justificar su posición. La defensa de la propiedad privada y del derecho a despido del personal (incluso de los primeros 33 operarios expulsados de la fábrica que incumplía el acuerdo del 17 de mayo) fueron elementos presentes en el discurso con el que la cúpula de Ford justificó su ataque contra la Comisión Interna y el Cuerpo de Delegados. El gobierno también legitimó el desalojo de la planta caracterizando la toma como un acto delictivo por fuera de los límites del Estado de Derecho. ${ }^{31}$ Esta concepción hacía posible, entonces, que el Poder Judicial pudiese autorizar el desalojo a manos de la fuerza policial.

No obstante, puede objetarse que la postura de la patronal y representantes del Estado no alcanzan para explicar la existencia de una construcción hegemónica, dado que los consensos deben buscarse también en los discursos y acciones reproducidos por los explotados. Por esa razón, resulta interesante intentar dar cuenta acerca de reacciones de algunos obreros involucrados en la ocupación fabril. Si bien resulta necesario profundizar dicho análisis, podemos citar, por ejemplo, a la prensa del PO la cual lamentaba que muchos de los operarios de la Ford hubiesen confiado en las promesas realizadas por el Ministerio de Trabajo, representantes parlamentarios, la Iglesia Católica y uno de los jueces que acudían a la planta durante la toma para, supuestamente, solucionar el conflicto. ${ }^{32}$ Esta postura parecería demostrar que las prácticas y discursos "democratizantes" del gobierno de Alfonsín, a las que refieren Glavich y Bonnet (1993 y 1994), habían impactado en la conciencia de muchos de los operarios de la planta automotriz. Probablemente la aceptación de esta concepción "democratizante" formaba parte de una construcción exitosa de hegemonía, traducida en la confianza en la dirigencia política y las instituciones democráticas para la solución de los conflictos entre capital y trabajo.

\section{Palabras finales}

En este escrito intentamos rescatar el caso de la ocupación de Ford Motor en 1985 articulándolo con un análisis político-cultural desde una perspectiva marxista. No desconocemos que los horizontes de esta investigación pueden ampliarse teniendo en cuenta otras fuentes (empresariales, estatales, sindicales, orales) y otras experiencias de ocupación de lugares de trabajo acontecidos en el mismo período que el de la planta automotriz de General Pacheco. No obstante, podemos esbozar una serie de conclusiones provisorias. En primer lugar, rescatamos la importancia de las organizaciones de izquierda en la experiencia y toma de conciencia de los operarios que motorizaron la ocupación de Ford. Los militantes del PCR (de mayor influencia en las acciones de la Comisión Interna), el MAS, el PC y el PO que formaban parte de la organización de base permitían a los operarios tener contacto con experiencias históricas de resistencia obrera. Estos partidos de izquierda resultaron de vital importancia en la toma de conciencia dado que su inserción en el lugar de trabajo colaboraba con la consolidación de una cultura residual en oposición a la cultura dominante expresada por el Estado y la patronal. Cabe aclarar que nuestro recorte se centró en la organización de base y, que por lo tanto, resulta necesario continuar investigando acerca de la influencia de los partidos en los operarios que acompañaron la toma sin pertenecer a los mismos. Podemos aventurar, que al menos durante la ocupación, los militantes de la organización de base fueron de importancia fundamental para canalizar las reivindicaciones de la mayoría en contra de los despidos de la patronal y articular las medidas de fuerza contra esta ofensiva.

También resta profundizar si los militantes de otras agrupaciones presentes en la planta, en particular el peronismo, también aportaron otras perspectivas y experiencias 
en esta lucha. Por ejemplo, la confianza en la Iglesia o en instituciones del Estado de un sector de los operarios, a las que aludía el PO, pueden entenderse, como dijimos, en el marco de construcción de consensos en torno al orden democrático, pero también entroncarse en la tradición peronista de alianza de clases y de su cercanía con la doctrina católica (presente también en gran parte de la clase obrera).

En segundo lugar, un tema colateral, pero no menor, fue el papel de la dirigencia sindical en este caso. En base a la entrevista realizada y al análisis de fuentes escritas, sostenemos que en la experiencia y conciencia de los operarios de Ford la cúpula del SMATA fue caracterizada como un "otro" que actuó en complicidad con el gobierno y la patronal. Esto nos lleva a definir a la dirigencia como una burocracia, es decir, una casta que dirige al movimiento obrero, que logra construir consensos al interior del mismo pero que no tiene sus mismos intereses de clase.

Finalmente, este estudio puede resultar un aporte al debate sobre la "derrota" o no del movimiento obrero en la coyuntura de los últimos años del "Proceso" y los primeros del orden democrático. Pablo Pozzi (2008) [1988] argumenta que la oposición obrera a la dictadura impidió a la burguesía romper el "empate hegemónico", concepto postulado por Juan Carlos Portantiero (1973) para explicar la imposibilidad de la clase dominante de imponer una dominación hegemónica en la sociedad argentina tras el golpe de Estado de 1955. Junto a Alejandro Schneider (1994), Pozzi también sugiere que dicho empate recién fue quebrado por el empresariado entre 1990 y 1993, tras las hiperinflaciones y la reforma neoliberal del menemismo con derrotas obreras muy profundas, como las ocurridas con los trabajadores estatales en las privatizaciones de empresas de servicios. Sin descartar la afirmación de estos autores, nos preguntamos si el empate hegemónico no comenzó a romperse con derrotas como la acontecida en Ford, la cual significó un duro golpe para la militancia de izquierda presente en los lugares de trabajo a manos del accionar conjunto de la patronal, el Estado y la dirigencia sindical. De ser así, podría pensarse que lo que la clase dominante no pudo concluir en los años setenta con el plan sistemático de terrorismo de Estado y con acciones como la intervención de sindicatos y la prohibición de huelgas, pudo lograrlo en la década siguiente con el apoyo de la cúpula gremial y un gobierno con prácticas y discursos basados en la demonización de las luchas del pasado reciente. 


\section{Q Bibliografía}

"Abdala, O. (2015). Rupturas y continuidades en las formas de acción y resistencia de los trabajadores. El caso Ford Motor Argentina. 1970-1985. (Tesina para obtener el título de Licenciado en Sociología). Instituto de Altos Estudios Sociales. UNSAM.

» Abós, A. (1986). El posperonismo. Buenos Aires: Legasa.

"Área de Economía y Tecnología (AEYT) de la Facultad Latinoamericana de Ciencias Sociales (FLACSO), Centro de Estudios Legales y Sociales (CELS), Programa Verdad y Justicia (PVJ) y Secretaría de Derechos Humanos (SDH) del Ministerio de Justicia y Derechos Humanos de la Nación (2016). Responsabilidad empresarial en delitos de lesa humanidad. Represión a trabajadores durante el terrorismo de Estado. Posadas: EdUNaM.

» Basualdo, V. (2006). "Complicidad patronal-militar en la última dictadura argentina: Los casos de Acindar, Astarsa, Dálmine Siderca, Ford, Ledesma y Mercedes Benz". Engranajes, Federación de Trabajadores de la Industria y Afines (FETIA), 5, 1-27.

"Belardinelli, P.(1994). "El marco político de la conflictividad obrera", en Villanueva, E. (coord.). Conflicto Obrero. Transición política, conflictividad obrera y comportamiento sindical en la Argentina 1984-1989. Buenos Aires: Universidad Nacional de Quilmes, pp. 103-149.

» Bonnet, A. y Glavich, E. (1993). “El huevo y la serpiente. Notas acerca de la crisis del régimen democrático de dominación y reestructuración capitalista en Argentina, 1983-1993" (Primera parte). Cuadernos del Sur, 16, 9-29.

» Bonnet, A. y Glavich, E. (1994). "El huevo y la serpiente. Notas acerca de la crisis del régimen democrático de dominación y reestructuración capitalista en Argentina, 1983-1993" (Segunda parte). Cuadernos del Sur, 17, 13-33.

»Damill, M. y Frenkel, R. (1993). “Restauración democrática y política económica: Argentina 1984-1991", en Morales, J. y McMahon, G. (comps.). La política económica en la transición democrática. Lecciones de Argentina, Bolivia, Chile y Uruguay. Santiago de Chile: CIEPLAN, pp. 33-95.

»Fernández, A. (1995). “Los roles del sindicalismo durante la transición democrática (1983-1995)". Revista de ciencias sociales, Universidad Nacional de Quilmes, 3, 213-228.

»García Allegrone, V. Partenio, F. y Fernández Álvarez, M. I. (2003). “Ocupaciones fabriles: un rastro en las experiencias históricas". VI Congreso Nacional de Estudios del Trabajo: "Los trabajadores y el trabajo en la crisis", Buenos Aires.

» Giniger, N., Guevara, M. y Rivero, C. (2010). “Las huellas del terrorismo de Estado sobre el movimiento obrero. Los casos de Ford y Acindar", en Figari, C., Lenguita, P. y Montes Cató, J. (comps.). El movimiento obrero en disputa. La organización colectiva de trabajadores, su lucha y resistencia en la Argentina del siglo XX. Buenos Aires: Ediciones Ciccus, pp. 143-162.

» Gramsci, A. (1999). Cuadernos de la cárcel. Tomo V. Edición crítica del Instituto Gramsci a cargo de Valentino Gerratana. México DF: Ediciones Era/Benemérita Universidad Autónoma de Puebla.

»Hernández, V. (1985). “La ocupación de fábrica como forma de lucha obrera. El 
caso de Ford Motors Argentina". Cuaderno CICSO, Serie Estudios, 62, 213-228.

»Iñigo Carrera, N. (2001). "Las huelgas generales, Argentina 1983-2001: un ejercicio de periodización”. Programa de Investigación sobre el Movimiento de la Sociedad Argentina (PIMSA), 5, 109-136.

» James, D. (1999). Resistencia e integración. El peronismo y la clase trabajadora argentina 1946-1976. Buenos Aires: Sudamérica.

»Laufer. R. (2017). “Clasismo y violencia obrera en el SMATA Córdoba: Las ocupaciones de Perdriel, 1970". Cuadernos de Marte, 12, 117-145.

»Lissandrello, G. (2013). "El Partido Comunista Revolucionario (PCR) y la discusión estratégica en los '70”. X Jornadas de Sociología, Facultad de Ciencias Sociales, Universidad de Buenos Aires, Buenos Aires.

»Löbbe, H. (2006). La guerrilla fabril. Clase Obrera e izquierda en la Coordinadora de Zona Norte del Gran Buenos Aires (1975-1976). Buenos Aires: Ediciones RyR.

»Lucita, E. (1985). “Elecciones sindicales y autoorganización obrera en la Argentina". Cuadernos del Sur, 3, 5-53.

» Massano, J. P. (2012). Reorganización del movimiento obrero sindicalizado en la posdictadura argentina. El caso de la "Ley Mucci" (Tesis de licenciatura). Universidad Nacional de La Plata, Facultad de Humanidades y Ciencias de la Educación, La Plata.

»Molinaro, L. (2013). "La democracia del Nunca más y el movimiento obrero. El caso de la ocupación obrera de la planta Ford de General Pacheco en 1985". Archivos de historia del movimiento obrero y la izquierda, 2, 55-75.

»Molinaro, L. (2016). "El reposicionamiento de la burocracia sindical en el ocaso del 'Proceso' (julio de 1982 - diciembre de 1983)". Archivos de historia del movimiento obrero y la izquierda, 8, 33-53.

»Molinaro, L. (2017). “Alrededor de ochenta días de lucha sin vueltas. El conflicto en el establecimiento de Volkswagen en Monte Chingolo (febrero-mayo de 1983)". A contracorriente. Una revista de historia social y literatura de América Latina, 14(3), 86-109.

»Murillo, M. V. (2010). “¿Las corporaciones o los votos?”; en Roberto GargareIla, María Victoria Murillo y Mario Pecheny (comps.). Discutir Alfonsín. Buenos Aires: Siglo XXI, pp. 139-159.

»Novaro, M. (2009). Argentina en el fin de siglo. Democracia, mercado y nación (1983-2001). Buenos Aires: Paidós.

»Novaro, M. y Palermo, V. (2013). La dictadura militar. Del golpe de Estado a la restauración democrática. Buenos Aires: Paidós.

»Ortiz, R. y Shorr, M. (2006). "La economía política del gobierno de Alfonsín: creciente subordinación al poder económico durante la 'década perdida'”, en Alfredo Pucciarelli (coord.). Los Años de Alfonsín. ¿El poder de la democracia o la democracia del poder?. Buenos Aires: Siglo XXI, pp. 291-333.

»Pesce, J. (2006). “Política y economía durante Alfonsín. La gestión del Ministro Grinspun", en Alfredo Pucciarelli (coord.). Los Años de Alfonsín. ¿El poder de la democracia o la democracia del poder?. Buenos Aires: Siglo XXI, pp. 367-412.

»Portantiero, J. C. (1973). "Clases dominantes y crisis políticas en la Argentina”; en Braun, Oscar (comp.). El capitalismo argentino en crisis. Buenos Aires: Siglo XXI, pp. 73-117. 
»Pozzi, P. (1988). Oposición obrera a la dictadura, 1976-1982. Buenos Aires: Contrapunto.

"Pozzi, P. y Schneider, A. (1994). "Combatiendo al capital”. Crisis y recomposición de la clase obrera argentina (1982-1992). Buenos Aires: El Bloque Editorial.

» Rubio, M. ““iViva nuestra justa lucha!’. Estrategia e inserción del Partido Comunista Revolucionario en el SMATA (1979-1985)”. Archivos de historia del movimiento obrero y la izquierda, 11, 143-162.

»Salas, E. (2006). La resistencia peronista. La toma del frigorífico Lisandro de la Torre. Buenos Aires: Retórica Ediciones.

» Samuel, R. (2006). The lost world of British communism. Londres: Verso Books. Extraído de: Mastrángelo, M. (2011). Rojos en la Córdoba obrera 1930-1943. Buenos Aires: Imago Mundi.

»Santella, A. (2008). Trabajadores, sindicato y conflictos en la industria automotriz. Un estudio de caso (1989-2006) (Tesis de doctorado) Universidad de Buenos Aires, Buenos Aires.

» Schneider, A. (2005). Los compañeros. Trabajadores, izquierda y peronismo (19551973). Buenos Aires: Imago Mundi.

» Senén González, S. y Bosoer, F. (1993). La trama gremial: 1983-1989. Buenos Aires: Corregidor.

»Thompson, E. P. (1989). Tradición, revuelta y conciencia de clase. Estudios sobre la crisis de la sociedad preindustrial. Madrid: Editorial Crítica.

»Varela, P. y Vasallo, D. (2016). “El disciplinamiento en la producción: la estrategia del SMATA en los lugares de trabajo"; en Varela, P. (coord.). El gigante fragmentado. Sindicatos, trabajadores y política durante el kirchnerismo. Buenos Aires: Final Abierto, pp. 51-93.

»Williams, R. (2009). Marxismo y Literatura. Buenos Aires: Las cuarenta.

"Zorzoli, L. (2015). "La normativa sindical entre la dictadura y el alfonsinismo, propuesta de sistematización”, en Schneider, A. y Ghigliani, P. (comps.). Clase obrera, sindicatos y Estado. Argentina (1955-2010). Buenos Aires: Imago Mundi, pp. 149-171. 